\title{
REFLEXÕES SOBRE O SUICÍDIO ASSISTIDO E EUTANÁSIA: UMA ANÁLISE SOB A ÓTICA DA DIGNIDADE HUMANA
}

\author{
Nilton Carlos de Almeida Coutinho ${ }^{1}$ \\ Viviane de Oliveira Martinez ${ }^{2}$
}

\begin{abstract}
Resumo: O direito à vida, enquanto direito fundamental, recebeu especial proteção por parte dos ordenamentos jurídicos ao longo dos anos vedando-se, inclusive, a prática do suicídio e da eutanásia. Neste artigo pretende-se refletir em que medida as normas e dogmas religiosos contribuíram para a adoção de determinados padrões éticos e morais aceitos pela coletividade e inseridos nos ordenamentos jurídicos (com ênfase no ordenamento jurídico brasileiro). Trata-se de uma pesquisa histórica e doutrinária, com base no método indutivo, tendo como foco principal a evolução do pensamento moderno sobre o tema, destacando-se aspectos relacionados à autonomia da vontade à a proteção da dignidade da pessoa humana.
\end{abstract}

Palavras-chave: eutanásia. Suicídio assistido. Direitos humanos. Vida. Dignidade.

\section{Introdução}

No Brasil, o direito constitucional segue as mais modernas tendências na área de direitos humanos, os quais foram construídos pelas várias revoluções e duas grandes guerras mundiais, nas quais "a humanidade compreendeu, mais do que em qualquer outra época da História, o valor supremo da dignidade humana" (COMPARATO, 2007, p. 56). Esse valor, apartado de qualquer significação religiosa, passou então a nortear a formação das novas constituições e instrumentos internacionais, incluindo-se a Constituição Federal de 1988.

Ocorre que no Brasil há "um importante percentual de idosos, que será crescente nos próximos anos" (MIRANDA; MENDES; SILVA, 2016, p. 518), e com ele, crescerão “também os casos de doenças crônicas e incapacitantes. Somado a isso, o maior enfoque da medicina humanizada e dos cuidados paliativos incitou debates sobre qualidade de morte em diversos países" (CASTRO et al., 2016, p. 362). No afã de se concretizar de forma cada vez mais ampla a dignidade da pessoa humana, discute-se acerca da possibilidade/necessidade do Estado disciplinar a eutanásia e o suicídio assistido.

\footnotetext{
${ }^{1}$ Doutor em Direito Político e Econômico pela Universidade Presbiteriana Mackenzie. Procurador do Estado de São Paulo, com atuação perante os Tribunais Superiores em Brasília. Professor junto ao Programa de Mestrado em Direito da Universidade Católica de Brasília. Professor junto ao Centro Universitário de Brasília (UNICEUB) e Instituto de Educação Superior de Brasília (IESB). Email: niltonpge@gmail.com

2 Procuradora da República. Mestranda em direito pela Universidade Católica de Brasília. E-mail: vmartinevi@hotmail.com
} 
De início faz-se necessário definir tais institutos, apontando suas principais semelhanças e diferenças.

Nesta linha, eutanásia significa "o emprego ou abstenção de procedimentos que permitem apressar ou provocar o óbito de um doente incurável, a fim de livrá-lo dos extremos sofrimentos que o assaltam ou em razão de outro motivo de ordem ética" (LEPARGNEUR, 1999, p. 43). Ela será ativa, no caso do emprego de um procedimento médico destinado a apressar a morte do paciente, ou passiva, na omissão proposital de uma ação médica que seria prolongadora da existência de uma vida. Quanto ao consentimento do enfermo, ela pode ser: voluntária, quando aproxima-se do suicídio assistido; involuntária, ocasião em que o ato é realizado contra a vontade do enfermo, ou seja, inquestionavelmente um homicídio, ou ainda; não voluntária, onde a vida é abreviada sem que se conheça a vontade do paciente (SIQUEIRA-BATISTA; SCRHAMM, 2005, p. 113-114). Já o suicídio assistido, por sua vez, diferencia-se da eutanásia pelo fato de que o médico auxilia o doente, prescrevendo-lhe a substância correta ou facilitando-lhe a injeção intravenosa dela, mas deixa ao alvedrio do enfermo a responsabilidade pelo ato final (KOVÁCS, 2015, p. 75) Segundo o Código Penal Brasileiro tais condutas podem caracterizar os crime de homicídio privilegiado (a depender das circunstâncias presentes no situação fática in concreto) ou auxílio a suicídio.

O objetivo desse artigo é analisar e a evolução do pensamento moderno sobre o tema e as principais correntes que defendem (ou proíbem) tais práticas, sob a tônica dos direitos humanos, com ênfase na autonomia da vontade e na dignidade da pessoa humana.

\section{DIREITOS DA PERSONALIDADE E A INFLUENCIA DA RELIGIÃO E DO LIBERALISMO NA DISCUSSÃO DA EUTANÁSIA E DO SUICÍDIO ASSISTIDO}

Os direitos da personalidade são concebidos como direitos inerentes à pessoa humana, abrangendo seus atributos físicos, psíquicos e morais, quer sejam considerados em relação a si mesma ou em relação aos outros indivíduos nas suas diversas atividades sociais. São direitos inatos e permanentes, nascem com a pessoa e a acompanham durante toda sua existência, tendo como finalidade primordial a proteção das qualidades e dos atributos que lhe são essenciais, de forma a salvaguardar sua dignidade e a impedir apropriações e agressões de particulares ou mesmo do próprio titular do direito. Fundam-se no respeito e na proteção da dignidade da pessoa humana, como elemento essencial à própria existência da pessoa, razão grande parte da doutrina os considera como direitos humanos fundamentais. (BELTRÃO, 2005, p. 50).

Dentre tais direitos, ganha relevância o direito à vida e o direito à vida digna, sendo certo que, para alguns autores, tais conceitos são indissociáveis, não sendo possível falar-se em vida sem que esta ocorra com dignidade. É dentro dessa ótica que a questão atinente à eutanásia e ao suicídio 
ganham força.

Da pesquisa bibliográfica sobre o tema atinente à eutanásia e ao suicídio extrai-se a existência de duas linhas principais de argumentação acerca do tema. Tais linhas, contudo, são diametralmente opostas com relação às suas conclusões com redação à possibilidade (ou não) da prática da eutanásia e do suicídio assistido. Assim, para a devida análise do tema, é necessário fazer algumas observações, ainda que suscintas em relação a cada uma dessas linhas.

\subsection{A influência da religião na vedação e na criminalização da eutanásia e do suicídio assistido}

A primeira linha de argumentação ética decorre de crenças oriundas de religiões monoteístas ao longo da história humana, que culminaram na interpretação da vida como algo sagrado. Neste aspecto, as origens desse manto de ilegalidade que cobre a eutanásia e a assistência ao suicídio residem nas crenças que se formaram ao longo da existência humana, por isso, no presente estudo, cabe buscar alguns indícios históricos do "processo de sacralização" da vida e da morte (SÁ; MOUREIRA, 2012).

De um modo geral, pode se afirmar que o suicídio vem se alternando durante a História entre um fato que não possui interesse jurídico e uma conduta criminosa, variação essa que tem implicações diretas na discussão dos temas afetos a este estudo.

Os primeiros grupos de homens, que viviam isolados em suas famílias, "encaravam a morte não como uma aniquilação do ser, mas como simples mudança de vida" (COULANGES, 2002, p. 13). Assim, por haver a crença de que a existência da pessoa continuava mesmo após ela estar enterrada em um túmulo, pelo fato de sua alma não se separar de seu corpo, não tinha sentido prático a noção de dar fim à própria vida.

Com o aprimoramento da vida em grupo e a consequente formação das cidades, destacando-se as civilizações grega e romana (COULANGES, 2002), o suicídio interessa ao direito somente na medida do dever que a pessoa tem de contribuir na manutenção da sua comunidade.

$\mathrm{Na}$ Roma antiga, pode se dizer que o suicídio, de um modo geral, era encarado como um direito de foro íntimo, sendo que, havendo motivos legítimos para a sua realização, o mesmo era até respeitado. Nem o Estado e nem a sociedade penalizavam sequer o auxílio a tal prática, sendo que nos escritos da época é possível observar que os romanos até discursavam sobre os modos de dar fim à própria vida (OLIVEIRA, 1994). Destaca-se na história o suicídio do imperador Nero, o qual, sentindo-se perseguido e prestes a ser derrotado e publicamente humilhado, "enterrou o ferro na garganta com a ajuda de seu secretário Epafródito" (SUETÔNIO, 2012, p. 230). Essa liberdade de ação, entretanto, não existia quando a pessoa estava sendo acusada em vida de um delito punível com o confisco e havia se "matado 'por temor' à pena imposta 'sobre o corpo e bens"” (JAKOBS, 2003a, p. 5). 
Na visão grega, os registros levam a crer que a morte honrosa era aquela ocorrida na vida ativa, em pleno campo de batalha, onde os homens seriam lembrados por sua juventude e coragem. Assim, o suicídio era tido como uma saída usada pelas mulheres e os poucos homens que o praticaram tinham como motivação evitar uma desonra ainda maior (MARQUETTI; MARQUETTI, 2017). Em acréscimo a esta visão mais romantizada, outros exemplos da literatura se dão no sentido de que o homem grego não poderia dispor de sua vida caso esta tivesse alguma utilidade ao Estado, sendo que, para se matar, teria que obter uma autorização do Senado (JUANATEY, 2004, p. 20).

Nos demais povos, na Idade Antiga, ao que se observa, em que pese a falta de registros históricos, o suicídio podia ser praticado como ato de honra ou de utilidade pública, no caso dos idosos e doentes incuráveis, sendo intolerado em outras situações, em função da utilidade econômica da vida ao grupo (JUANATEY, 2004, p. 13-34).

Com a queda dos impérios grego e romano, as religiões, antes politeístas, passaram a pregar a existência de um Deus único. Nesse contexto, pode se dizer que foi com o advento das religiões monoteístas que o suicídio veio a ser definitivamente encarado como um comportamento que interessava à religião.

Na Idade Média, caracterizada pelo pouco desenvolvimento cultural e científico, devido ao controle da Igreja sobre o Estado, a qual colocava a fé como único caminho a seguir, consolidou-se também a ilegalidade do suicídio assistido e da eutanásia. No islamismo, "a vida é considerada inviolável, não podendo o homem dela dispor e, assim, condutas como a eutanásia e o suicídio são reprováveis e condenadas" (COSTA, 2017, p. 68). Atualmente, dentre as religiões predominantes no mundo, "somente no budismo é possível visualizar um traço de aceitação acerca do suicídio" (COSTA, 2017, p. 71), desde que o suicida já tenha alcançado o objetivo da vida, que é a iluminação, e encontre-se com a mente livre do egoísmo e do desejo (COSTA, 2017, p. 71). Mesmo assim, ele não justifica a prática da eutanásia e do auxílio ao suicídio.

No cristianismo, segmento religioso mais popular do mundo, a condenação ao suicídio veio sendo construída com o passar do tempo. A Bíblia Sagrada, livro religioso mais popular do mundo, já trazia narrações de suicídios, principalmente no Antigo Testamento, aceito por judeus e cristãos. As narrações referentes aos suicídios dos reis Saul e Zinri demonstravam uma desapreciação da conduta, mas, com relação a Sansão, que teria provocado o desabamento de um templo sobre si e todos que ali dentro se encontravam para evitar a vitória dos filisteus, agindo em função da fé para salvar o povo de Israel, não havia que se cogitar de um pecado imperdoável (ALEXANDRINO, 2017).

Foi a igreja católica, maior responsável pela propagação do cristianismo sobre a Terra, que promoveu a equiparação do suicídio ao assassinato, através, principalmente dos ensinamentos de 
Santo Agostinho, o qual, sob a égide do mandamento não matarás, ensinou que "nem a outro nem a ti próprio matarás pois quem a si próprio se mata, mata um homem" (1996, p. 158, apud BRUNHARI; DARRIBA, 2010).

A partir de então, diversos concílios da igreja católica definiram que os suicidas deveriam ser privados dos ritos fúnebres da Igreja, bem como impedidos de ser enterrados em cemitérios sacros (BRUNHARI; DARRIBA, 2010). Na sociedade alemã, JAKOBS narra que os bens dos suicidas eram confiscados e que os cadáveres eram enterrados em "sepulturas de asnos" (2003a, p. 5-6), fazendo referência a uma passagem de Jeremias, do antigo testamento da Bíblia.

Tendo a legislação medieval dos países cristãos também autorizado o confisco dos bens do suicida (CARNEIRO, 2013), pode se dizer que, devido à estreita ligação entre Igreja Católica e Estado, a condenação do suicídio reverteu-se economicamente aos interesses das sociedades medievais e, consequentemente, restou cristalizada, principalmente no Ocidente, a necessidade de reprimir a criminalização da eutanásia e do suicídio assistido.

O catolicismo imperou também em Portugal, país que colonizou e governou o Brasil até 1822 e que trouxe para cá suas Ordenações, incluindo-se as Filipinas, nas quais, em razão da grande influência religiosa, havia previsão até mesmo da criminalização de ofensa a mandamentos cristãos (BICALHO, 2000). Após 100 anos da proclamação da independência, a igreja católica, mesmo tendo sido separada do Estado, passou a atuar diretamente na área política do país, participando, inclusive, do processo constituinte que deu origem à CF vigente (AZEVEDO, 2004, p. 112-113).

Atualmente, a Igreja Católica vem perdendo seguidores, mas em compensação, está aumentando o número de pessoas de outras religiões que também adotam a Bíblia Sagrada, as quais elegem representantes no Poder Legislativo para defenderem seus pontos de vista religiosos (BORGES, 2007, p.62-65). Com base nisso, pode se dizer, com grau acurado de certeza, que o cristianismo, embora não seja oficialmente adotado pela nossa ordem constitucional, direciona diversas pautas legislativas.

Não bastasse isso, cabe ressaltar que a prática reiterada e secular de determinada doutrina religiosa a coloca no inconsciente, individual e coletivo. Como pontua JUNG, "ideias religiosas são, como prova a história, de uma força sugestiva e emocional extremas" (2000, p. 74), de modo que "alguém pode, de boa-fé, convencer-se de que não tem ideias religiosas. Mas ninguém pode colocar-se à margem da humanidade, de forma a não ter nenhuma représentation collective dominante" (JUNG, 2000, p. 74).

Essa influência é muito visível no direito brasileiro. SILVA, ao falar do direito à vida, enfatizou que a "vida humana é expressão da natureza no seu mais elevado sentido. É obra de Deus que o direito, natural ou positivo, reconhece como sendo de supremo valor" (2006, p. 37). PEREIRA, ao falar sobre o tema, é enfático ao dizer que "agrada a mente e a alma, detectar-se, no 
pensamento médico contemporâneo, acendrado respeito à vida humana e à ética médica, acatando, inclusive, o conceito da Igreja Católica sobre eutanásia” (2002, p. 20-21). Embora não se possa confirmar nem refutar o quanto, de fato, o pensamento católico esteja arraigado nos profissionais de saúde, sem olvidar da questão apontada acima por JUNG, os exemplos apresentados são emblemáticos acerca da influência da doutrina católica no direito pátrio.

\subsection{O liberalismo como contraponto à dogmática religiosa e como base da evolução da proteção dos direitos humanos}

A questão da vedação total à assistência ao suicídio e à eutanásia ficou sedimentada na raça humana com o advento de religiões monoteístas, especialmente do cristianismo. No século XVIII, entretanto, houve uma retomada das concepções filosóficas desvinculadas do pensamento religioso. Nesse cenário, surgem as contribuições dos filósofos empiristas e céticos, dentre os quais pode se destacar David Hume.

Hume abordou várias questões de natureza filosófica de maneira cética, retirando delas o fundo religioso que dava a tônica até então. Seu argumento se dava no sentido de que não havia um "eu" que permaneceria no tempo. Também ressaltou em seu trabalho a irracionalidade dos milagres e a falácia das religiões que se apoiavam neles para demonstrarem o seu poder. Questionou a moral sob o ponto de vista religioso, fundamentando-a puramente no bem-estar que as ações boas podem gerar ao homem.

As concepções de Hume influenciaram profundamente a obra de Immanuel Kant, o qual apresentou o homem como um ser racional e dotado de vontade livre (COMPARATO, 2007, p. 21).

Kant dividiu seu pensamento filosófico em 3 partes: "lógica, que é a filosofia formal aplicada a todo o pensamento; física, que lida com a natureza e descreve o mundo como ele é; e ética, que tem como objeto a vontade humana e prescreve o que ela deve ser" (BARROSO, 2014, p. 69-70).

Sobre a ética, que se encontra no domínio da moral, ele disse que a mesma é composta por comandos ou imperativos, que podem ser hipotéticos, quando uma ação é boa para o alcance de uma finalidade, ou categóricos, quando referentes a uma ação que é boa em si mesma (BARROSO, 2014, p. 70). A partir daí, ele conclui que “o imperativo categórico é, portanto, só um único, que é este: Age apenas segundo uma máxima tal que possas ao mesmo tempo querer que ela se torne lei universal" (KANT, 2007, p. 59).

Ao passar a ideia do imperativo categórico universal, Kant fundamenta seu pensamento na racionalidade do homem: "em todas as suas ações, tanto nas que se dirigem a ele mesmo como nas que se dirigem a outros seres racionais, ele tem sempre de ser considerado simultaneamente como fim” (KANT, 2007, p. 68). 
Em consequência da própria racionalidade, o filósofo enfatiza a autonomia da vontade como "único princípio da moral" e que o homem deve agir "de modo a que as máximas da escolha estejam incluídas simultaneamente, no querer mesmo, como lei universal” (KANT, 2007, p. 8586). Para que isso seja possível, ele lembra que a autonomia "é, pois, o fundamento da dignidade da natureza humana e de toda a natureza racional" (p. 79).

Ao falar sobre primazia da dignidade da pessoa humana e da autonomia da vontade, Kant marca o fim do jusnaturalismo teológico ou medieval, dando seguimento ao jusnaturalismo racionalista ou moderno, onde inicia-se um processo de desvinculação da religião ao direito, colocando o homem, e não a divindade, como fim deste.

A defesa da autonomia da vontade inspira a independência norte-americana, as declarações de direitos que surgiram após a Revolução Francesa (COMPARATO, 2007, p. 128-158), bem como muitas ordens constitucionais que vieram posteriormente.

No início do século XX, com as catástrofes decorrentes das duas guerras mundiais, houve um encontro do "pensamento kantiano, com as ideias de moralidade, dignidade, Direito cosmopolita e paz perpétua" (PIOVESAN, 2015, p. 46), ressurgindo como ideia central a dignidade da pessoa humana, a qual tem norteado diversos ordenamentos jurídicos, incluindo-se nossa CF vigente.

A partir da desvinculação entre moral e religião, trazida pelo liberalismo, emerge a possibilidade de reconstrução de um direito que não é dirigido ao atendimento de um ser divino, sepultando-se a defesa jurídica da sacralidade de qualquer interesse. Essas ideias nortearam a formação de novas ordens constitucionais, divorciadas da fé, onde a dignidade humana é o fim principal do direito. No caso ora sob debate, o liberalismo e a dignidade da pessoa humana levam à possibilidade de legalização do homicídio assistido e da eutanásia, de modo que embasam a argumentação de todos que são a favor de tais práticas.

\section{PARADIGMAS SOBRE EUTANÁSIA E SUICÍDIO ASSISTIDO NO ORDENAMENTO JURÍDICO ESTRANGEIRO}

Não obstante o objetivo principal deste artigo seja refletir acerca da eutanásia e do suicídio assistido no âmbito do ordenamento jurídico brasileiro, faz-se necessário observar como alguns ordenamentos jurídicos estrangeiros tem enfrentado esta questão.

Como já descrito, o conflito entre religião e liberalismo permeia discussões pelo mundo inteiro, sendo que na maioria dos países, tal como aqui, eutanásia e suicídio assistido são condutas proibidas. Observe-se, entretanto que tais condutas já foram legalizadas e disciplinadas, isolada ou cumulativamente, em diversos países, tais como Holanda, Bélgica, Suíça, Luxemburgo, Colômbia, Canadá e em sete estados dos EUA (CASTRO et al., 2016, p. 367).

$\mathrm{Na}$ Europa tem-se que diversos países da Comunidade Europeia firmaram a "Convenção 
sobre os Direitos do Homem e da Biomedicina”, conhecida como Convenção de Oviedo, a qual, em seu artigo $2 .^{\circ}$ já predispõe que, na medicina, "o interesse e o bem-estar do ser humano devem prevalecer sobre o interesse único da sociedade ou da ciência" (CONSELHO EUROPEU, 1997). Com base nela, não há nenhuma ofensa a direitos humanos no fato de um país autorizar eutanásia e suicídio assistido.

A convenção também trouxe a necessidade de atualização das premissas que norteiam a prática médica nos países que aderiram tal pacto. A relação médico-paciente era caraterizada pela submissão do segundo à decisão incontestável do primeiro, conforme ensinamento abaixo transcrito:

\begin{abstract}
"O antigo contrato entre o médico e a sociedade era implícito, sendo que nele estava prevista uma forte autonomia do grupo profissional. A comunidade médica, por sua vez, estabelecia seus próprios padrões, onde os médicos faziam o melhor que podiam, sempre sabendo o que era certo para um paciente. Este, por sua vez, devia ter fé cega em seu médico, afinal, ele sempre fazia o melhor que podia. A qualidade do médico era um padrão que não podia ser colocado em dúvida." (WESTERVELD et al., 2005, p. 369)3
\end{abstract}

Atualmente, com a Convenção de Oviedo, bem como pelo próprio amadurecimento social, esse antigo contrato está em xeque. Na Itália, por exemplo, um país de tradição católica ainda muito evidente, está em fase de aprovação projeto de lei que versa sobre o testamento biológico como documento legal que exprime as diretivas da pessoa em relação aos procedimentos médicos que desejará no fim da vida, de modo a prevalecer a vontade do paciente, ao invés da decisão do médico, como é de costume naquele país (OBREGON; SOUZA, 2018, p. 1452-1453). Na Holanda, onde eutanásia e suicídio assistidos são práticas legalizadas, há um consenso de que não existe nenhum dever do médico em sobrepor sua vontade à da pessoa sob seus cuidados, ainda que a vida desta esteja em jogo (WESTERVELD et al., 2005, p. 369). Está ocorrendo uma mudança de enfoque na atividade médica na Europa, onde o profissional passa seguir protocolos e padrões de conduta ditados por atos normativos estatais (op. cit.), bem como a se submeter ao dever de informação, explicando ao seu assistido, da forma mais detalhada e clara possível, as opções de tratamento médico que lhe estão disponíveis, bem como as possíveis consequências de cada uma, deixando a decisão final a cargo do paciente.

A aplicação da Convenção de Oviedo nos países europeus tem sido feita também pelo Tribunal Europeu de Direitos Humanos (TEDH), cujas decisões oferecem importantes

\footnotetext{
${ }^{3}$ Tradução livre de: The old contract between doctor and society was implicit and based on a strong autonomy of the professional group. The professional group set its own standards, doctors did the best they could and knew what was right for a patient. The patient was expected to have blind faith in the doctor, after all, he did the best he could. The quality of the doctor was never doubted and did not have to be established, it was a given.
} 
contribuições à atualização da atividade interpretativa dos direitos humanos. Tal corte já analisou casos de ortotanásia e suicídio assistido, sendo que dois deles oferecem subsídios relevantes ao presente estudo e, por isso, serão descritos abaixo.

\subsection{Caso Lambert e outros versus França ${ }^{4}$}

A ortotanásia "pode ser demarcada como a morte no seu tempo certo, sem os tratamentos desproporcionais (distanásia) e sem abreviação do processo de morrer (eutanásia)" (SIQUEIRABATISTA; SCHRAMM, 2005, p. 114) e, na prática, ela implica em deixar de aplicar ao paciente tratamentos médicos que prolonguem artificialmente a vida, deixando esta seguir seu curso natural. Logo, teoricamente, não estaria ela no objeto deste estudo. No entanto, conforme a visão religiosa de determinado grupo social, a ortotanásia é também uma forma de eutanásia, sendo que o julgado em questão, no qual os pais de Vincent Lambert, em estado de coma irreversível, pedem ao TEDH que, em virtude de suas convicções religiosas, não seja suspendida a alimentação e hidratação artificial do filho, ilustra muito claramente esse conflito.

Ao decidir o caso, o TEDH embasou-se na Convenção de Oviedo, bem como no Guia sobre o Processo de Tomada de Decisão em Relação ao Tratamento Médico em Situações de Fim de Vida, também do Conselho Europeu, que prescreve diretrizes sobre nutrição e hidratação artificial, terminando por negar aos suplicantes qualquer pedido em relação à França, uma vez que o Estado não havia praticado nenhuma ilegalidade em face de Vincent. Cita-se, a seguir, posição da corte sobre o tema:

"Nas circunstâncias do caso, a Corte reitera que cabe principalmente às
autoridades nacionais verificar se a decisão de retirar o tratamento é compatível
com a legislação interna e a Convenção, bem como estabelecer os desejos do
paciente de acordo com a legislação nacional. O papel do Tribunal consistiu em
averiguar se o Estado havia cumprido suas obrigações positivas, nos termos do

\footnotetext{
${ }^{4}$ Síntese fática do caso Lambert and others v. France: Vincent Lambert, francês, sofreu um acidente de trânsito quando tinha 32 anos, que o deixou tetraplégico e em estado de total dependência para os atos da vida cotidiana. O Estado lhe prestou serviços de saúde de forma mais ampla possível, tendo tentado sua reabilitação de todas as formas, não conseguindo fazer com que o mesmo sequer se comunicasse mediante o movimento dos olhos. Em 2011, ele foi avaliado por um grupo de médicos, que concluiu que ele estava em estado neurovegetativo crônico caracterizado como minimamente consciente. Mesmo assim, lhe foram administradas várias sessões de fisioterapia, sem um mínimo de sucesso. A partir de 2012, os médicos perceberam que ele manifestava resistência aos cuidados médicos que lhe ministravam e, com a concordância da esposa de Vincent, passaram a aplicar a Lei Leonetti, que disciplina procedimentos relativos ao fim da vida na França, suspendendo o fornecimento de hidratação e alimentação artificial. Os pais de Vincent e dois de seus irmãos, devido a um compromisso religioso de manutenção da vida, obtiveram uma liminar da justiça francesa para restabelecer a alimentação e hidratação artificial dele. Após novas reuniões e nova análise do caso por vários médicos, decidiu-se que a alimentação e a hidratação só serviam para sustentar artificialmente a vida. Os pais e irmão de Vincent recorreram até o Conselho de Estado, mas, depois de nove perícias médicas, do pronunciamento do Comitê Nacional de Medicina e do próprio relator da Lei Leonetti, não obtiveram um provimento favorável dessa corte. Foi então que recorreram ao TEDH (TEDH, 2015).
} 
Artigo 2 da Convenção.” (TEDH, 2015) $)^{5}$

Para a mencionada corte europeia, basta que o país aplique corretamente sua legislação e que esta não afronte a Convenção de Oviedo. Nesse sentido, no próprio corpo do julgado, ela descreve outros casos, em que cidadãos da Itália e do Reino Unido não tiveram direito ao suicídio assistido porque as legislações de seus Estados não permitiam, sendo que tal proibição também não ofendia a Convenção de Oviedo.

Pode se extrair, do estudo desse caso, que a existência de leis e procedimentos estatais claros em questões de saúde, bem como o consentimento do doente ou de quem lhe faça as vezes, é que são determinantes na questão sobre o respeito a direitos humanos, não podendo as convicções religiosas ter influência na lei ou na vontade do próprio paciente.

\subsection{Caso Gross versus Suíça ${ }^{6}$}

O julgamento do caso foi interrompido em 2013, mesmo assim sua discussão é relevante ao presente estudo. Ele foi proposto em face da Suíça por Alda Gross, a qual pedia ter acesso à medicação necessária ao suicídio assistido, conforme o procedimento da lei daquele país.

Ao decidir sobre a demanda de Alda, o TEDH entendeu que a incerteza dos protocolos de ética médica, que fundamentaram posições conflitantes entre médicos, os quais ora diziam que ela tinha direito ao suicídio e ora não, contrariedades essas que não foram dirimidas a contento pela

\footnotetext{
${ }^{5}$ Tradução livre de: In the circumstances of the case, the Court reiterates that it was primarily for the domestic authorities to verify whether the decision to withdraw treatment was compatible with the domestic legislation and the Convention, and to establish the patient's wishes in accordance with national law.
}

\footnotetext{
${ }^{6}$ Síntese fática do caso Gross v. Switzerland: ela nasceu em 1931 e, ao chegar na velhice, expressou seu desejo de acabar com sua vida, uma vez que estava se tornando cada vez mais frágil com o passar do tempo e não estava disposta a continuar sofrendo com a agravação de seus problemas físicos e mentais. Em 2005, ela tentou cometer suicídio, sem êxito, razão pela qual passou seis meses internada em um hospital psiquiátrico. Ao concluir seu tratamento, a sra. Gross conta que teve medo de não conseguir seu intento novamente e, por tal motivo, ela queria terminar sua vida tomando uma dose letal de pentobarbital sódico, substância química utilizada em casos de suicídio assistido. Ao entrar em contato com a EXIT, uma associação dedicada à morte com dignidade, esta respondeu que seria difícil encontrar um médico que quisesse lhe fornecer receita médica para o medicamento letal. Em 2008, um psiquiatra a examinou e garantiu que ela tinha capacidade de formar o seu próprio juízo, bem como, embora ela não fosse portadora de nenhuma doença terminal, já apresentava sinais avançados de declínio de suas faculdades físicas e, bem como sinais de decrepitude mental. Além disso, já não tinha possibilidade de conviver com amigos e familiares, não tendo mais nenhum interesse pelos assuntos da vida. No entanto, tal médico não pôde, sozinho, prescrever a medicação, sendo que ela não encontrou outro profissional que o fizesse. Um dos profissionais disse que poderia prescrever apenas se tivesse uma salvo-conduto, uma vez que Alda não era portadora de doenças terminais. Alda passou então a litigar pelo seu direito ao pentobarbital sódico e seu caso foi analisado pela Suprema Corte Suíça, a qual, em 2010, entendeu que a exigência de uma prescrição médica servia a proteger o indivíduo de tomar uma decisão precipitada, bem como de prevenir abusos, sendo que Alda não teria direito ao medicamento sem uma receita. Finalmente, aquela corte entendeu que a suplicante teria que se submeter a um acompanhamento médico de longo prazo, por um profissional especialista pudesse lhe emitir a receita. Foi então que ela decidiu levar seu caso ao TEDH (TEDH, 2013).
} 
Suprema Corte do país demandado, o qual disse que ela somente poderia ter o direito se se submetesse a um procedimento longo e não disciplinado na lei, gerou à requerente um considerável grau de angústia. Para o Tribunal, o Estado teria o dever de dar diretrizes claras, definindo, com certeza, as circunstâncias sob as quais os médicos estariam autorizados a emitir uma receita solicitada por indivíduo que tomou uma decisão séria, no exercício do seu livre arbítrio, de pôr fim à sua vida, mas onde a morte não seria iminente. Para o TEDH, houve falha do Estado em emitir essas regras e, portanto, uma violação ao artigo $8 .^{\circ}$ da Convenção Europeia de Direitos Humanos ${ }^{7}$. Tal discussão, contudo, não chegou a ser concluída porque Alda Gross morreu e ela seria a única interessada diretamente no julgamento (TEDH, 2013).

Embora essa discussão não tenha sido levada até o fim, dali se pode extrair que a corte, mais uma vez, apontava ao Estado litigante a necessidade de definir o assunto por regras claras, não interferindo no conteúdo delas.

Conforme se pode observar dos dois julgados, os julgadores do TEDH, tendo por limite a soberania legislativa de cada país e por norte as Convenções celebradas pelos Estados-parte, não apontam, em nenhum momento, que eutanásia e suicídio assistido são violações aos direitos humanos, bem como não colocam como determinante em seus julgados sobre o assunto a dogmática religiosa de sacralidade e absolutismo do direito à vida.

Em busca na HUDOC database (que é o sítio oficial de pesquisa de jurisprudência do TEDH) não se obteve - até a conclusão deste artigo - nenhum caso onde Holanda, Luxemburgo, Bélgica ou Suíça tenham violado a Convenção de Oviedo por permitirem a prática de eutanásia ou suicídio assistido. No Relatório Anual 2017/18 da Anistia Internacional sobre a situação dos direitos humanos no mundo (ANISTIA INTERNACIONAL, 2018, p. 91, 277, 348), não há nenhuma observação em relação aos aspectos ora estudados (o documento não engloba Luxemburgo). Com isso, pode se afirmar que tais países não sustentam nenhuma tradição de violadores de direitos humanos no cenário mundial no que diz respeito à morte assistida. Além disso, a Organização para a Cooperação e Desenvolvimento Económico aponta que tais países possuem índices de saúde superiores a 8 (em uma escala de 1 a 10) de modo não há como duvidar da boa qualidade de serviços médicos que oferecem aos seus povos. Por isso, pode se concluir que a legislação deles pode ser

\footnotetext{
${ }^{7}$ Artigo $8 .{ }^{\circ}$ 1. Qualquer pessoa tem direito ao respeito da sua vida privada e familiar, do seu domić́lio e da sua correspondência.

2. Não pode haver ingerência da autoridade pública no exercício deste direito senão quando esta ingerência estiver prevista na lei e constituir uma providência que, numa sociedade democrática, seja necessária para a segurança nacional, para a segurança pública, para o bem-estar econômico do país, a defesa da ordem e a prevenção das infracções penais, a proteção da saúde ou da moral, ou a proteção dos direitos e das liberdades de terceiros. (CONSELHO EUROPEU, 1950)
} 
usada como referência para a implementação segura e regrada de eutanásia e suicídio assistido.

A legislação da Holanda é a mais abrangente, pois regula a realização de ambos. Médicos podem terminar a vida ou fornecer medicação a maiores de 12 anos que saibam expressar sua vontade, os quais deverão ser assistidos pelos pais ou responsável até os 18 anos. Para não serem responsabilizados criminalmente, os médicos devem: a) ter um pedido escrito e fundamentado do paciente; b) ter a convicção de que o sofrimento do paciente é duradouro e insuportável; c) informar o paciente sobre a situação que se encontra e lhe dar perspectivas de seu prognóstico; d) verificar se o paciente tem a convicção de que lhe será a melhor solução e; e) obter um parecer no mesmo sentido de um segundo médico. As atividades dos médicos são supervisionadas por comitês regionais, sendo que todos os parâmetros são oferecidos e fiscalizados pelo governo do país, conforme disposto na Lei de Terminação da Vida a Pedido e de Suicídio Assistido (Procedimentos de Revisão) (HOLANDA, 2001).

A partir do exposto, pode se dizer que, embora o argumento religioso ainda predomine pelo mundo no que diz respeito à proibição da eutanásia e do suicídio assistido, oito países já autorizam tais práticas. Além disso, o TEDH já decidiu que ambos são práticas legítimas, no limite da soberania legislativa de cada país, pois encontram supedâneo na Convenção de Oviedo. Através do posicionamento dessa alta corte, que serve como parâmetro de referência para os direitos humanos, não só em nível europeu, como também mundial, resta claro que suicídio assistido e eutanásia não são condutas que importem em ofensa a direitos humanos. Pelo que se extrai da experiência de países estrangeiros, tendo a Holanda como exemplo de referência, pode se concluir que a prática regrada de eutanásia e suicídio assistido, controlada por órgão externo e pelo Estado, é suficiente para a prevenção de eventuais abusos. Na medida em que a vontade do paciente é imprescindível, tais países não desrespeitam os argumentos de caráter religioso, de modo a dar uma interpretação mais moderna do princípio da dignidade da pessoa humana.

\section{REFLEXÕES ACERCA DA INCONSTITUCIONALIDADE DA REPRESSÃO CRIMINAL AO SUICÍDIO ASSISTIDO E À EUTANÁSIA}

O suicídio, no Brasil, tem sido encarado como um problema de saúde mental (OMS, 2006), sendo, inclusive, objeto de estudos epidemiológicos (CALIXTO FILHO; ZERBINI, 2016). Nesses casos, ele é um evento que interessa mais à psicologia e à medicina do que ao direito, o qual age pontualmente apenas para evitar que terceiros agravem o transtorno mental, bem como para legitimar condutas de salvamento ao suicida.

Contudo, pessoas acometidas de doenças terminais ou incuráveis que causam intenso sofrimento, quando conscientemente tomam a decisão de se suicidar, não são doentes mentais e, 
portanto, não podem ser tratadas de maneira mais gravosa do que se fossem, de modo que a elas não pode ser negado um direito que é conferido àqueles que encontram-se no gozo de sua capacidade física.

Desse modo, tem-se que, no suicídio a pessoa, ao exercer sua liberdade, opta por deixar de exercer o direito à vida. Mesmo assim, pode se afirmar, sem sombra de dúvidas, que o ordenamento jurídico não tem por intenção vedar a prática de tal ato, o qual pode ser executado por pessoas fisicamente capazes, sem que dele resultem sanções de qualquer espécie. Ainda que seja proibida a ajuda proposital de terceiros, a mesma não se faz minimamente necessária àqueles que gozam de capacidade física.

Um outro aspecto mencionado pela doutrina acerca impossibilidade de repressão criminal ao suicídio assistido e à eutanásia baseia-se no fato de que a criminalização destas condutas vai contra a laicidade do Estado e à liberdade religiosa, expressamente adotadas pela nossa ordem constitucional. Nesse aspecto, o item 3 do artigo 18 do Pacto Internacional de Direitos Civis e Políticos, internalizado no Brasil, é elucidativo:

3. A liberdade de manifestar a própria religião ou crença estará sujeita apenas às limitações previstas em lei e que se façam necessárias para proteger a segurança, a ordem, a saúde ou a moral públicas ou os direitos e as liberdades das demais pessoas. (BRASIL, 1992)

Assim, pela leitura do referido dispositivo, bem como dos incisos VI e VIII do artigo $5 .^{\circ}$ da $\mathrm{CF} / 88$, verifica-se não ser mais aceita nenhuma interferência da religião na atividade legislativa estatal, inclusive na seara penal, cujas sanções envolvem privação da liberdade. Além disso, o Estado somente está autorizado a agir para garantir a liberdade individual de crença religiosa, restringindo-a ao mínimo possível, para que outros também possam exercê-la. "A ordem jurídica em um Estado Democrático de Direito não pode se converter na voz exclusiva da moral de qualquer religião" (PIOVESAN, p. 56-57), de modo que a CF definitivamente impede uma atuação estatal voltada para a proteção de crenças, sempre que elas implicarem na invasão da esfera de direitos de alguém.

\subsection{Da punibilidade do suicídio assistido e da eutanásia}

Os direitos fundamentais são, em princípio, o fruto de um processo de amadurecimento de princípios tidos como éticos, surgidos na própria vivência social, cuja escopo teleológico é o de proteção do homem, intrinsecamente considerado. Eles "refletem um construído axiológico, a partir de um espaço simbólico de luta e ação social" (PIOVESAN. 2015, p. 44). 
Em tal processo de construção axiológica, a raça humana passou por muitos estágios de socialização, saindo do núcleo familiar para a vida na cidade e, durante todas essas mudanças, os direitos inerentes ao homem vêm sendo reconhecidos, inclusive, de forma universalizada (PIOVESAN, 2015, p. 52-56), cada vez mais tendo como norte o ser humano e sua existência digna. Essa busca da dignidade remete aos direitos elencados no caput do artigo 5. da nossa CF, e se dá, em regra, de forma harmônica, ou seja, as condutas e as prestações estatais destinadas à preservação de um levam, automaticamente, à do outro.

No centro das discussões sobre eutanásia e suicídio assistido sempre estará em jogo o interesse de uma pessoa mentalmente sã, padecendo de intenso sofrimento físico, a qual "pede à sociedade é que respeite, dentro do possível, o seu modo de enfocar e viver a morte" (SÁ; MOUREIRA, 2012, p. 12), suplicando para que não lhe sejam negados os meios necessários para a sua decisão, seja ela a de viver doente até a ocorrência natural da morte ou a de antecipar este evento.

Para aqueles que decidem esperar a morte natural, o Poder Público deve se ocupar de oferecer um sistema de saúde adequado, investindo em cuidados paliativos (CASTRO et al., 2016, p. 362). Outrossim, para quem decide exercer seu direito de antecipar a própria morte, o Estado deve proteger a vontade livre e consciente de levar a cabo tal intento, ao não impedir a imprescindível ajuda de terceiros, principalmente porque a possibilidade de ofertar meios de morte mais humanitários às pessoas mentalmente capazes, ou que tomaram a decisão de morrer antecipadamente quando ainda o eram, envolve a participação de profissionais da saúde, o que influi na ética médica e, notadamente, no direito. Essa proteção desafia, então, uma interpretação mais abrangente e realista do princípio da dignidade da pessoa humana, no sentido de que uma vida só é totalmente digna quando acompanhada de uma "morte digna" (SÁ; MOUREIRA, 2012, p. 9), onde surge a necessidade de debater a eutanásia e o suicídio assistido.

No direito comparado, tais condutas são admitidas, isolada ou cumulativamente, na Holanda, Bélgica, Suíça, Colômbia, Luxemburgo, Canadá e em sete estados dos EUA (CASTRO et al., 2016, p. 367). No Uruguai, a eutanásia é isenta de pena (COSTA, 2017, p. 147). Embora cada país tenha suas regras próprias, um traço em comum entre as legislações ou decisões que permitem a eutanásia e o suicídio assistido é a necessidade de que o doente tenha sido informado de sua condição e, principalmente, que tenha manifestado seu desejo de morrer antecipadamente. Pode se dizer, então, que tanto a eutanásia, quanto o suicídio assistido, quando praticados a pedido de uma pessoa que se encontre no gozo de sua saúde mental ou encontrava-se quando o fez, objetivam resgatar a mesma possibilidade de exercer os direitos que tinha antes da doença e que são garantidos a todos. 
No que diz respeito ao direito à vida, este tem sido tradicionalmente tutelado pelo direito penal brasileiro. A Constituição de 1824 já trazia em seu bojo, no Título 8. ${ }^{\circ}$, o reconhecimento a direitos e garantias civis e políticos dos cidadãos brasileiros, sendo que, sob sua égide, ainda vigoravam as Ordenações Filipinas, as quais já previam em seu bojo a criminalização do homicídio e da ofensa aos mandamentos cristãos (BICALHO, 2000).

Embora não tenha a Constituição expressamente se referido a tal direito fundamental, ela já previa, no artigo 179, XVIII, a elaboração de um Código Criminal, o que ocorreu em1830. Nele, já constava a proibição do homicídio, em seu artigo 192, e também, ao auxílio ao suicídio, no artigo 196 (BRASIL, 1830). Nos anos 1990, com o advento da República e de uma nova CF, a situação permaneceu a mesma, ou seja, o direito à vida continuou a ser protegido, nos mesmos moldes da lei penal anterior, pelo CP de 1890, bem como pelo atual, no Título I do Capítulo I da Parte Especial.

\subsection{Da autonomia da vontade e seus reflexos em relação à eutanásia e ao suicídio assistido}

Nos delitos de homicídio e de induzimento, instigação ou auxílio ao suicídio, em hipóteses diversas das ora debatidas, é inquestionável a ocorrência do "injusto de matar o outro" (JAKOBS, 2003b, p. 39) ou de incentivá-lo a um comportamento auto lesivo, que tem consequências desastrosas na saúde pública. Logo, a proteção penal se dá em nome tanto do direito à vida, como em defesa da liberdade e, por isso, é sempre aceita.

No entanto, sob profunda influência religiosa, o direito penal brasileiro, desde as ordenações, até o CP vigente, manteve-se inalterado quanto às mudanças da sociedade, de modo que legislador ordinário ainda não buscou conciliar a proteção da vida tradicionalmente conferida pelos delitos de homicídio e induzimento, instigação ou auxílio ao suicídio, descritos nos artigos 121 e 122 do CP, com a liberdade de autonomia e, principalmente, com o respeito à dignidade da pessoa humana envolvidos na eutanásia e no suicídio assistido.

É importante ainda salientar que, mesmo a sociedade brasileira tendo passado por profundas mudanças, abraçando, inclusive, pactos internacionais de proteção aos direitos humanos em sua ordem constitucional (FERREIRA FILHO, 2016, p. 108), a legislação penal tende, contra a vontade do próprio titular, a sacralizar o exercício do direito à vida, em detrimento da liberdade, embora ambos tenham, inclusive topologicamente, a mesma posição na CF (SARLET, 2012, p. 66).

Registre-se, ainda, a figura do chamado testamento vital, o qual é formulado com o intuito de projetar seus efeitos ainda em vida - eficácia inter vivos - do declarante, porém em instante no qual ele não tenha mais condições de lucidamente externar sua declaração de vontade (DONNINI e LEMOS, 2017, p. 314). Nesse sentido, a lei poderia ampliar a validade do testamento vital, que, na proteção dos direitos fundamentais, analisasse se, por exemplo, o testamento vital demonstrando a inequívoca decisão de uma pessoa acerca de suas diretivas de vontade em relação 
à vida e à morte - seria ou não válido no ordenamento jurídico brasileiro. Ademais, por meio dele ter-se-ia a segurança de que o doente exerce sua vontade de forma livre e informada (BORGES, 2007, p. 240), mesmo em hipóteses de inconsciência futura.

Assim, a partir desse documento, as demais questões de saúde podem ser comprovadas por laudos médicos, de modo a não dificultar ainda mais a execução de uma decisão tão ou mais dolorosa do que a própria doença que a motiva.

Todavia, enquanto persistir essa falta do legislador, as pessoas que possuem melhor situação financeira poderão contar com auxílio para a morte digna em outros locais, como por exemplo, na Dignitas, instituição suíça dedicada a tal finalidade (COSTA, 2017, p. 149).

Ainda que exista um "senso inato de autopreservação que leva os indivíduos a buscarem comportamentos e contextos que denotem maior longevidade durante a vida" (SANTOS; FARO, 2018, p. 1), durante os anos vindouros esses casos tenderão a ser mais ocorrentes, em razão do aumento da população idosa. Por isso, a atuação do Poder Legislativo e, na falta dela, a do Poder Judiciário, serão imprescindíveis à plena garantia da dignidade da pessoa humana.

Sendo assim, sob a ótica da máxima realização dos direitos fundamentais, ainda é possível defender-se que, diante da omissão do Poder Legislativo em face dos direitos fundamentais envolvidos na questão (SARLET, 2012, p. 272), ao Poder Judiciário está aberta a possibilidade de não criminalizar condutas legítimas de eutanásia e de assistência ao suicídio, com base na dignidade da pessoa humana, considerada como norma de efetividade imediata (PRETTO, 2007, p.6-7).

Deste modo, adotando-se a ideia de ALEXY, de que "as colisões entre princípios devem ser resolvidas por meio da definição de uma relação de precedência" (ALEXY, p. 164), entende-se que o Poder Judiciário, ciente de que não há nenhum grau de hierarquia entre a vida e a liberdade, poderá se dirigir ao ponto de chegada definido pela $\mathrm{CF}$, que é a dignidade da pessoa humana.

Sabemos que a autonomia privada é o poder atribuído pelo ordenamento jurídico ao indivíduo para que este possa reger, com efeitos jurídicos, suas próprias relações. Contudo, tal poder de disposição não pode, de nenhuma forma, violar o núcleo substancial de tais direitos, eis que todos os indivíduos (incluindo o seu titular) devem respeitá-los

\section{Conclusões}

A sociedade, durante a História, tem incorporado muitas regras de conduta impostas pela religião em seus padrões morais. Assim, no decorrer da História, a adoção de religiões monoteístas, predominantemente cristãs, levaram a uma influência da Igreja no direito, de modo que o suicídio, a assistência a ele e a eutanásia, considerados como pecado, passaram também a ser tratados como crime. 
Desde final do século XVIII, entretanto, tem havido um movimento de separação das esferas religiosa e jurídica, o qual é embasado na importância inerente do próprio homem. Nossa ordem constitucional abraçou essa ideia, centrando a sociedade brasileira na dignidade da pessoa humana, a qual vai orientar a aplicação e o exercício dos direitos fundamentais.

No caso da eutanásia e do suicídio assistido estão em jogo o exercício da vida e da liberdade. Ainda que o cristianismo pregue uma sacralização e, consequentemente, uma sobreposição da primeira sobre a segunda, a Constituição da República Federativa do Brasil não permite a perpetuação desse entendimento, tendo em vista a laicidade do estado, a liberdade de crenças e a plena busca da dignidade.

No Brasil, país que segue o que há de mais contemporâneo na área de direitos humanos, embora o suicídio não seja mais considerado um crime, ainda há a repressão penal à eutanásia e ao suicídio assistido

O tema ainda é bastante controverso na doutrina e jurisprudência pátria, tendo em vista a existência de um conflito entre direitos fundamentais, quais sejam: o direito à vida e o direito à liberdade no que se refere à autonomia da vontade.

Assim, em que pese a existência de argumentos aptos a coibir e também a legitimar a prática do suicídio assistido e da eutanásia pelos portadores de doenças terminais ou incuráveis que causam sofrimento físico intenso, tem-se que a tese acerca da vedação de práticas de eutanásia e suicídio assistido têm prevalecido no ordenamento jurídico brasileiro.

A dignidade da pessoa humana é o valor fundante que alicerça e embasa a proteção dos demais direitos reconhecidos pelo ordenamento jurídico. Contudo, tratando-se de direitos fundamentais é necessário ponderar, no caso concreto, se a manutenção (ou não) da vida é a decisão que melhor atende ao princípio da dignidade humana. Aliás, é ela (a dignidade da pessoa humana) o núcleo essencial dos direitos fundamentais, devendo - sempre - ser protegida em eventual colisão entre direitos.

É certo que o consentimento por parte do titular do direito pode, em determinadas hipóteses, limitar a proteção de um determinado direito seu. Contudo, exige-se que o consentimento seja válido, ou seja, não poderá viole a lei, a ordem pública, a moral ou os bons costumes. Até porque, a manifestação de vontade contrária à própria dignidade não poderia ser aceita em nosso ordenamento jurídico.

Os argumentos aqui apresentados constituem-se como elementos que deverão ser levados em consideração pelo Poder Judiciário no julgamento de casos que lhe sejam apresentados, analisando-se todos os elementos relacionados a morte, vida e dignidade do ser humano.

Assim, a indisponibilidade do direito à vida e a autonomia da vontade se constituem como direitos fundamentais do indivíduo que devem ser devidamente apreciados pelo julgador, a fim de 
que se possa - efetivamente - obter-se uma decisão justa à luz do princípio da dignidade da pessoa humana e respeito aos direitos fundamentais.

É nessa linha que os projetos de leis relacionados ao tema (com ênfase nas propostas de alteração do Código Penal brasileiro) devem caminhar: rumo a uma maior (e melhor) proteção dos direitos humanos e à preservação da dignidade humana enquanto direito intangível (e não como decisões políticas lastreadas em posicionamentos religiosos ou convicções pessoais).

\section{ASSISTED SUICIDE AND EUTHANASIA: A HISTORICAL EVOLUTIONARY ANALYSIS UNDER THE OPTICS OF HUMAN DIGNITY}

Abstract: The right to life, as a fundamental right, has received special protection from the legal systems over the years, including the practice of suicide and euthanasia. In this article we intend to reflect the extent to which religious norms and dogmas contributed to the adoption of certain ethical and moral standards accepted by the community and inserted in the legal systems (with emphasis in the Brazilian legal system). It is a historical and doctrinaire research, based on the inductive method, having as main focus the evolution of the modern thought on the subject, emphasizing aspects related to the autonomy of the will to the protection of the dignity of the human person..

Keywords: euthanasia. Assisted suicide. Human rights. Life. Dignity.

\section{Referências bibliográficas:}

ALEXANDRINO, Alan Rennê. O suicídio da razão. Revista Teologia Brasileira. São Paulo, n. 64, 2017. Disponível em: $<$ http://www.teologiabrasileira.com.br/teologiadet.asp? codigo=567 $>$. Acesso em: 22 out. 2018.

ALEXY, Robert. Teoria dos direitos fundamentais. Trad. Virgílio Afonso da Silva. São Paulo: Malheiros Editores, 2008.

AZEVEDO, Dermi. A Igreja Católica e seu papel político no Brasil. Estudos avançados, São Paulo, v. 18, n. 52, p. 109-120, dez. 2004 . Disponível em:

$<$ http://www.scielo.br/scielo.php?script=sci_arttext\&pid=S0103$\underline{40142004000300009 \& \operatorname{lng}=\mathrm{en} \& \mathrm{nrm}=\mathrm{iso}>}>$. Acesso em: 13 Nov. 2018.

BELTRÃO, Silvio Romero. Direitos da personalidade. De acordo com o novo código civil. São Paulo: Atlas, 2005 
BARROSO, Luís Roberto. A dignidade da pessoa humana no direito constitucional contemporâneo: a construção de um conceito jurídico à luz da jurisprudência mundial. Trad. Humberto Laport de Mello.1. ed. 3. reimpr. Belo Horizonte: Fórum, 2014.

BICALHO, Maria Fernanda Baptista. Crime e castigo em Portugal e seu império. Topoi, Rio de Janeiro, v. 1, n. 1, p. 224-231, jan-dez. 2000. Disponível em:

$<$ http://www.scielo.br/pdf/topoi/v1n1/2237-101X-topoi-1-01-00224.pdf > . Acesso em: 09 out. 2018.

BORGES, Tiago Daher Padovezi. Representação partidária e a presença dos evangélicos na política brasileira. 2007. 151 f. Dissertação (mestrado) - Universidade de São Paulo, São Paulo.

BRASIL. Constituição (1824). Constituição Política do Império do Brasil: registrada em 22 de abril de 1824. Rio de Janeiro: [s.n.], 1824. Disponível em: $<$ http://www.planalto.gov.br/ccivil_03/constituicao/constituicao24.htm >. Acesso em: 09 out. 2018.

. Lei de 16 de dezembro de 1830. Código Criminal, Rio de Janeiro: 08 jan. 1831.

Disponivel em: <http://www.planalto.gov.br/ccivil_03/leis/lim/LIM-16-12-1830.htm >. Acesso em: 09 out. 2018.

. Decreto n. ${ }^{\circ}$ 592, de 6 de julho de 1992. Pacto internacional sobre direitos civis e políticos. Brasília: 07 de julho de 1992. Disponível em: < http://www.planalto.gov.br/ccivil_03/decreto/1990-1994/d0592.htm > . Acesso em: 14 nov. 2018.

BRUNHARI, Marcos Vinicius; DARRIBA, Vinícius Anciães. Não te matarás: suicídio, prevenção e, psicanálise. Estudos de psicanálise. Belo Horizonte, n. 34, p. 63-70, dez. 2010 . Disponível em $<$ http://pepsic.bvsalud.org/scielo.php?script=sci arttext\&pid=S0100$\underline{34372010000200009}$ >. Acesso em: 22 out. 2018.

CALIXTO FILHO, Magid; ZERBINI, alita. Epidemiologia do suicídio no Brasil entre os anos de 2000 e 2010. Saúde, Ética \& Justiça. São Paulo, v. 21, n. 2, p. 45-51, 2016. Disponível em: <file://C:/Users/PRSP/Downloads/134006-Texto\%20do\%20artigo-257773-2-10-20170630.pdf>. Acesso em: 26 nov. 2018. 
CARNEIRO, Anna Bárbara de Freitas. Suicídio, religião e cultura: reflexões a partir da obra Sunset Limited. Reverso, Belo Horizonte , v. 35, n. 65, p. 15-23, jul. 2013 . Disponível em: $<\underline{\text { http://pepsic.bvsalud.org/scielo.php?script }=\text { sci arttext\&pid }=\mathrm{S} 0102-}$ 73952013000100002\&lng=pt\&nrm=iso>. Acesso em: 22 out. 2018.

CASTRO, Mariana Parreiras Reis de et al. Eutanásia e suicídio assistido em países ocidentais: revisão sistemática. Revista Bioética, Brasília, v. 24, n. 2, p. 355-367, 2016 . Disponível em:

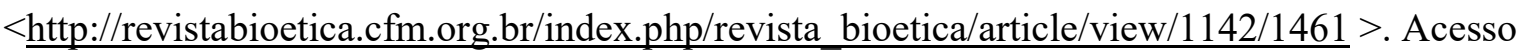
em: 12 nov. 2018.

COMPARATO, Fábio Konder. A afirmação histórica dos direitos humanos. 5 ed. rev. e atual. São Paulo: Saraiva, 2007.

COSTA, Fernanda Otero. $O$ direito entre a vida dada e a vida construída: reflexões sobre eutanásia e suicídio assistido. Rio de Janeiro: Lumen Juris, 2017.

COUlAngeS, Fustel de. A cidade Antiga. Trad. Jean Melvile. São Paulo: Martin Claret, 2002.

DONNINI, Rogério; LEMOS, Raphael Abs Musa de. Dignidade e autonomia: a ponte dogmática para o testamento vital. In: Quaestio Iuris. vol.10, $\mathrm{n}^{\mathrm{o}}$. 01, Rio de Janeiro, 2017.

DWORKIN, Ronald. Life's dominion. Nova Iorque: Vintage books Edition, 1994.

.O império do direito. Trad. Jeferson Luiz Camargo. 3 ed. São Paulo: Martins Fontes, 2014.

FERREIRA FILHO, Manoel Gonçalves. Direitos Humanos Fundamentais. 15 ed. São Paulo: Saraiva, 2016.

FIESER, James. David Hume (1711-1776).Internet Encyclopedia of Philosophy. Tenessee. [20--]. Disponível em : <https://www.iep.utm.edu/hume/>. Acesso em: 23 out. 2018.

JACINTHO, Jussara Maria Moreno. Dignidade Humana: princípio constitucional. Curitiba: Juruá, 2006 
JAKOBS, Günther. Suicídio, eutanásia e direito penal. Trad. Maurício Antônio Ribeiro Lopes. Barueri, SP: Manole, 2003a.

JAKOBS, Günther. Teoria da pena e suicídio e homicídio a pedido. Trad. Maurício Antônio Ribeiro Lopes. Barueri, SP: Manole, $2003 b$.

JUANATEY, Carmen. EI derecho y la muerte voluntaria. Coyoacán: Distribuciones Fontamara, 2004.

JUNG, Carl Gustav. Os arquétipos e o inconsciente coletivo. Trad. Maria Luíza Appy e Dora Mariana R. Ferreira da Silva. Petrópolis, RJ: Editora Vozes, 2000.

KANT, Immanuel. Fundamentação da metafísica dos costumes. Trad. Paulo Quintela. Lisboa: Edições 70 Lda, 2007.

KIRSTE, Stephan. O direito humano fundamental à democracia. Rev. direitos fundam. democ.,Curitiba, v. 20, n. 20, p. 5-38, jul-dez. 2016. Disponível em:

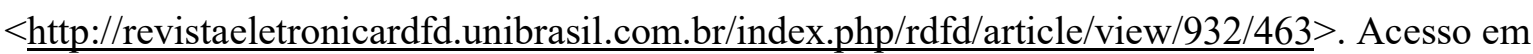
14 nov. 2018.

KOVÁCS, Maria Júlia. Suicídio assistido e morte com dignidade: conflitos éticos. Revista Brasileira de Psicologia, Salvador, Bahia, v. 2, n. 1, p. 5-14, 2015. Disponível em: $<$ http://revpsi.org/wp-content/uploads/2015/04/Kov\%C3\%A1cs-2015-Suic\%C3\%ADdioassistido-e-morte-com-dignidade-Conflitos-\%C3\%A9ticos.pdf > . Acesso em: 12 nov. 2018.

LEPARGNEUR, Hubert. Bioética da eutanásia: argumentos éticos em torno da eutanásia. Revista Bioética. Brasília, v. 7, n. 1, p. 41-8, 1999.

MARQUETTI, Flávia Regina; MARQUETTI, Fernanda Cristina. Suicídio e feminilidades.Cad. Pagu, Campinas , n. 49, e174921, 2017 . Disponível em

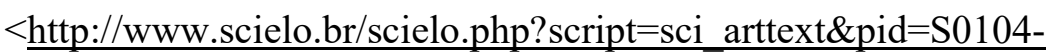

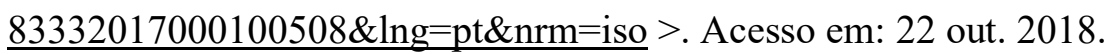

MIRANDA, Gabriella Morais Duarte; MENDES, Antonio da Cruz Gouveia; SILVA, Ana Lucia Andrade. O envelhecimento populacional brasileiro: desafios e consequências sociais atuais e 
futuras. Revista Brasileira de Geriatria e Gerontologia, Rio de Janeiro, v. 19, n. p. 507-519, 2016. Disponível em: < $\underline{\text { http://www.scielo.br/pdf/rbgg/v19n3/pt_1809-9823-rbgg-19-03-00507.pdf }}$ >. Acesso em: 13 nov. 2018.

OLIVEIRA, Francisco de. Suicídio na Roma Antiga. Revista Máthesis, Viseu, n. 3, p. 65-93, 1994. Disponível em: < $\underline{\text { https://digitalis- }}$ dsp.uc.pt/bitstream/10316.2/23985/1/mathesis3 artigo5.pdf?ln=pt-pt $>$. Acesso em: 22 out. 2018.

ORGANIZAÇÃO MUNDIAL DE SAÚDE (OMS). PREVENÇÃO DO SUICÍDIO: UM RECURSO PARA CONSELHEIROS. Genebra, 2006. Disponível em:

$<$ http://www.who.int/mental health/media/counsellors portuguese.pdf $>$. Acesso em $>13$ nov. 2018.

PEREIRA, Hugo. O doente terminal: aspectos jurídicos. Revista de Jurisprudência do Tribunal de Justiça do Estado do Ceará, Fortaleza, v.9, p. 11-21, 2002. Disponível em: < https://www.tjce.jus.br/wp-content/uploads/2015/07/revista jurisprudencia 09.pdf $>$. Acesso em: 14 nov. 2018.

PIOVESAN, Flávia. Direitos humanos e justiça internacional: um estudo comparativo dos sistemas regionais europeu, interamericano e africano. 6. ed. rev. ampl. e atual. São Paulo: Saraiva, 2015.

PRETTO, Ana Lúcia. Jurisdição constitucional na Constituição Federal de 1988: entre ativismo e auto-contenção. Rev. direitos fundam. democ.,Curitiba, v. 2, n. 2, p. 1-33, jul-dez. 2007.

Disponível em: $<$ http://revistaeletronicardfd.unibrasil.com.br/index.php/rdfd/article/view/108/107 >. Acesso em 26 nov. 2018.

RIBEIRO, Diaulas Costa; MORAES, José Diniz de. direito à morte (eutanásia) na Constituição Federal: uma visão semiótico-bioética. In: REPATS - Revista de Estudos e Pesquisas Avançadas do Terceiro Setor. Brasília, V. 3, nº 1, p.323-345, Jan-Jun, 2016. Disponível em: < https://portalrevistas.ucb.br/index.php/REPATS/article/view/7357/pdf> Acesso em: 28 dez. 2018.

SÁ, Maria de Fátima Freire de; MOUREIRA, Diogo Luna. Autonomia para morrer: eutanásia, suicídio assistido e diretivas antecipadas de vontade. Belo Horizonte: Del Rey, 2012. 
SANTOS, Luana Cristina Silva; FARO, André. Aspectos conceituais da conduta autolesiva: uma revisão teórica. Psicol. Pesqui. Juiz de Fora, n. 12(1), p. 1-10, jan-abr. 2018. Disponível em:< http://pepsic.bvsalud.org/pdf/psipesq/v12n1/02.pdf > . Acesso em: 12 nov. 2018.

SARLET, Ingo Wolfgang. A Eficácia dos Direitos Fundamentais: Uma Teoria Geral dos Direitos Fundamentais na Perspectiva Constitucional. 11 ed. rev. atual. Porto Alegre: Livraria do Advogado Editora, 2012.

SILVA, Jose Carlos Sousa. Direito à vida. Porto Alegre: S. A. Fabris, 2006.

SUETÔNIO. A vida dos 12 césares. Brasília: Edições do Senado Federal, 2012.

SIQUEIRA-BATISTA, Rodrigo; SCHRAMM, Fermin. Conversações sobre a "boa morte": o debate bioético acerca da eutanásia. Cadernos de Saúde Pública. Rio de Janeiro, v. 21, n. 1, p.

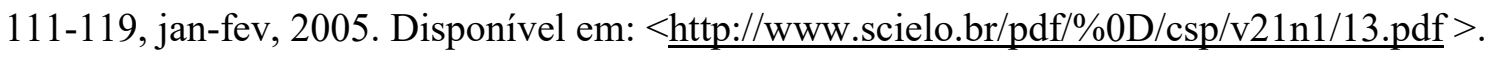
Acesso em 24 out.2018.

Trabalho enviado em 14 de janeiro de 2019

Aceito em 17 de março de 2019 